\title{
Mobile SNS Addiction and User Continuance: An Empirical Investigation of WeChat
}

\author{
Li FANG, Qihua LIU
}

\begin{abstract}
Mobile social networking sites (SNS) have become one of the most popular means of online social interactions. However, that excessive and uncontrolled SNS use may have negative consequences. Recent statistics show that use of mobile SNS can be addictive for some individuals, which can lead to some significant behavioural or psychological problems. This study has extended the dual-process continuance model by examining the impact of users' levels of addiction as important factors that influence their continuance intention to use WeChat, as one of the most popular mobile SNS in China. Structural equation modelling was used to validate the proposed models and assumptions. Based on survey data from 495 valid responses of WeChat users, we found that the level of mobile SNS addiction augments users' perceptions of perceived usefulness, perceived enjoyment, trusting beliefs and habit, whereas it has no impact on users' satisfaction and loyalty. It can serve as a platform for future research on technology addiction, and for better understanding of addiction-driven system overuse behaviours and their effects on users. The results suggest that the increase in usage time and frequency of use does not necessarily mean higher satisfaction and loyalty to the mobile SNS, perhaps certain addictive symptoms occurring.
\end{abstract}

Keywords: belief systems; continuance usage intention; mobile social network sites; SNS addiction; SNS continuance; technology addiction

\section{INTRODUCTION}

Mobile devices such as tablets, smart phones, and portable computers are becoming increasingly penetrated among people [1]. Under the guarantee of being available anywhere and anytime, users are frequently utilizing mobile devices to connect and interact with their families, friends, colleagues and communities in virtue of social network sites today [2]. Referring to the most popular and excessively utilized mobile SNS, Facebook and WeChat stand out. As of the first quarter of 2018, the number of monthly active Facebook users has reached 1.45 billion. WeChat is the largest mobile SNSs in China. By September 2018, the number of monthly active WeChat users has reached 1 billion.

To uncover the mechanism behind why mobile SNSs are adopted quickly by heterogeneous groups in terms of age, gender, culture, language, etc., and figure out which factors are effective in this process is imperative [3]. Multitudes of research have examined the stimulating factors for adopting intention on the purpose of better understanding the initial adoption decision of SNS. While initially studies have often extended the theoretical core of the technology acceptance model (TAM) to explain adoption process [4-6], it is noticeable that more and more theories and models such as theory of planned behavior (TPB) [7], the uses and gratifications (U\&G) theory [8] and the social influence processes framework [9] are used and tested.

Along with the rapidly increasing number of mobile SNS users, information systems (IS) researchers' attention on mobile SNS usage behaviors has shifted from initial use to continued, post-adoption usage decisions. Drawing from theories of user satisfaction and information adoption, some research has applied the expectation-confirmation model (ECM) and expanded it within the mobile SNS context $[10,11]$. Besides, sense of community (SOC), selfregulation framework and the dual-process theories also have been applied in mobile SNS continuance [12-15].

Most of the above literature has assumed that the use of mobile SNS is a positive phenomenon that should be promoted through a more subtle understanding of the key factors of system-referenced perceptions [16]. However, several studies have suggested that excessive and uncontrolled mobile SNS use may have negative consequences $[17,18]$. Owing to technology characteristics, such as complexity, uncertainty, and SNSspecific characteristics as to social overload, more and more users have recently experienced stress and feelings of strain caused by excessive use of mobile SNS [17]. Excessive engagement in mobile SNS has been regarded as having potential for addictive use [18]. Mobile SNS use can be addictive in that it can make up for social voids in people's lives and bring in unremitting thrills, which may appeal vulnerable brains. Furthermore, an increasing number of users being addicted to mobile SNS has already become a fact $[19,20]$.

Extant research indicates that individuals manage to rationalize unjustified abnormal behaviors as a result of addictions distorting user's perceptions. Turel et al. (2011) proposed and empirically validated that technology addiction indeed distorted user perceptions of usefulness, ease of use, and enjoyment of the system to which users are addicted, which is one of the seminal and influential MIS works on technology addiction [16]. Recent studies of SNS adoption also have discussed the addictive influences of such technologies on users usage behaviors [17][21], however, most of them focused on the impact of addiction on user initial adoption decision of mobile SNS. There are few studies on the impacts of addiction on user continued usage behaviours of mobile SNS.

This study has extended the dual-process continuance model by examining the impact of users' levels of addiction as important factors that influence their continuance intention to use WeChat, as one of the most popular mobile SNS in China. Structural equation modelling was used to validate the proposed models and assumptions. Based on survey data from 495 valid responses of WeChat users, we found that that the level of mobile SNS addiction augments users' perceptions of perceived usefulness, perceived enjoyment, trusting beliefs and habit, whereas it has no impact on users' satisfaction and loyalty. It can serve as a platform for future technology addiction research, and for better understanding of addiction-driven system overuse behaviours and their effects on users. The results suggest that the increase in 
usage time and frequency of use does not necessarily mean higher satisfaction and loyalty to the mobile SNS, perhaps certain addictive symptoms occurring.

\section{THEORETICAL BACKGROUND AND RESEARCH MODEL}

\subsection{Mobile SNS Addiction}

Technology addiction encapsulates a psychological dependency on the use of an information technology, which is a special type of behavioural addiction [22]. Based on Turel et al. (2011)'s definition, "technology addiction is often manifested through a number of symptoms, such as salience, withdrawal, conflict, relapse and reinstatement, tolerance, and mood modification" [16]. One's level of technology addiction is consistent with the magnitude of associated symptoms of technology addiction the user has been obsessed with and the degree of psychological dependency on the technology. The concept of technology addiction has transcended pure technology overuse or high level of interaction with technology. It is also distinct from the notion of habit, because habit often describes automatic action owing to learning [23], which has nothing to do with psychological dependency. In other words, overuse of technology, automatic use of technology or overuse of technology is not necessarily technically addiction.

Mobile SNS addiction is an instance of technology addiction. In line with the definition of technology addiction, mobile SNS addiction can be describe as a psychological state of maladaptive dependency on the mobile SNS use to such a degree that the following distinctive behavioral addiction symptoms appear: salience, conflict, relapse and reinstatement, withdrawal symptoms, tolerance, and mood modification.

Addictive mobile SNS-use has been observed in many studies. According to $\mathrm{Xu}$ and Tan (2012), a host of individuals expend a lot of time on SNS every day, which can cause some social and psychological problems such as SNS addiction [24]. Likewise, the online-survey, Rosen et al. (2013) campaigned on 1143 subjects, demonstrated that the number of one's Facebook friends was bound up with symptoms regarding narcissism and histrionic personality disorders [19]. Salehan and Negahban (2013) harbored the idea that engagement in mobile SNS is a significant predictor of mobile addiction [25]. Also, the degree of social anxiety has been discussed as a mediator of the effects of SNS-use [20]. Jeong et al. (2016) found that SNS use predicted smartphone addiction better than game use, although both of them were positive predictors of smartphone addiction [18].

\subsection{Mobile SNS Continued Usage}

The number of mobile SNS users has been growing at an astonishing rate in recent years and SNS is increasingly utilized for individuals to socially interact with one another, as part of routine activities. Because of inordinate mobile SNS pouring into users' attention and limited time they own, a multitude of mobile SNS, incorporating the renowned MySpace, have been abandoned by a great amount of users [14]. Due to the emergence of a large number of competitors and the worryingly high abandonment rate, it will be very important for each mobile
SNS to better understand the key factors that affect users' continued usage [14].

A lot of prior research has examined the determinants of mobile SNS continuance. In general, the extant SNS continuance models can be mainly classified as analytic based (AB) models, the emotion based (EB) models, and the habit/automaticity perspective (HAP) [14]. The AB model explains the continuance intention of mobile SNS users mainly through the use of the theory of reasoned action (TRA) and TAM. Perceived usefulness, perceived enjoyment and trusting beliefs are the three post adoption beliefs in $\mathrm{AB}$ models. EB models recognize that the emotion is very important in decision making. The existing literature on mobile SNS continuance and user retention mostly uses satisfaction and loyalty as a key factor in predicting continuance intentions $[11,13,14]$. The HAP focuses on the important role of habits in the continued use of mobile SNS users.

Human cognition is often determined by multiple processes and their interactions, not simply controlled by a single process [14]. In fact, there are direct or indirect connections between the intrinsic beliefs of $\mathrm{AB}$ models, EB models and HAP models in the context of mobile SNS. According to the dual-process theories, Gwebu et al. (2014) absorbed the key components of the competitive continuous model to theoretically integrate the above three models, and tested the potential value of the integrated model [14]. This research uses the integrated model to examine the users' continuance intention of WeChat, a popular mobile SNS in China. Thus we propose that:

H1. Perceived usefulness has a positive effect on continuance intention toward WeChat.

H2. Trusting beliefs have a positive effect on continuance intention toward WeChat.

H3. Perceived enjoyment has a positive effect on continuance intention toward WeChat.

H4. Satisfaction has a positive effect on continuance intention toward WeChat.

H5. Loyalty has a positive effect on continuance intention toward WeChat.

H6. Satisfaction has a positive effect on loyalty toward WeChat.

H7. Perceived usefulness has a positive effect on satisfaction toward WeChat.

H8. Trusting beliefs have a positive effect on satisfaction toward WeChat.

H9. Perceived enjoyment has a positive effect on satisfaction toward WeChat.

H10. Perceived usefulness has a positive effect on loyalty toward WeChat.

H11. Trusting beliefs have a positive effect on loyalty toward WeChat.

H12. Perceived enjoyment has a positive effect on loyalty toward WeChat.

H13. Habit has a positive effect on continuance intention toward WeChat.

H14. Habit positively mediates the relationship between perceived usefulness and continuance intention.

H15. Habit positively mediates the relationship between trusting beliefs and continuance intention.

H16. Habit positively mediates the relationship between perceived enjoyment and continuance intention. 


\subsection{Integrating Mobile SNS Addiction with Continuance}

Becker and Murphy (1988) suggested that every user, regardless of the addiction level of his/her, would invariably follow a reasoned action process with expectation to maximize utility; that is, he/she takes into account an extended set of technology perceptions when forming continuance intention toward mobile SNS [26]. Turel et al. (2011) has pointed out that when users experience symptoms of technical addiction, their brains are rewired so that they are highly allergic to rewards and other stimuli (from WeChat in our case), which modify their perception system [16]. Moreover, addiction gives rise to more frequent system use, more specifically, the higher user is addicted, the higher intrinsic and extrinsic utilities are to be achieved, and then his/her perceptions and continuance intention is awoken by a behavior evaluation feedback mechanism [27]. Meanwhile, Maier et al. (2014) indicated that, besides perceptual beliefs, addiction was also able to influence intentions concerning whether a technology should be used continuously or not [17]. Further, users who are addicted develop dilated continuance intentions of the technology [14]. In fact, previous research has confirmed that addicted users exaggerate their evaluation of computer games compared to non-addicted people [28]. Therefore, in terms of WeChat, there may exist a similar intensification of positive continuance. We therefore propose the assumption that users with higher level of addiction accordingly develop more positive intention on continuous usage of WeChat.

Perceived usefulness, trusting beliefs, perceived enjoyment, satisfaction, loyalty and habit are the six key components of the dual-process continuance model proposed by Gwebu et al. (2014). Our research expands the model by integrating it with SNS addiction. Hence, we propose the following:

H17: The level of SNS addiction has a positive impact on perceived usefulness toward WeChat.

H18: The level of SNS addiction has a positive impact on perceived enjoyment toward WeChat.

H19: The level of SNS addiction has a positive impact on trusting beliefs toward WeChat.

H20: The level of SNS addiction has a positive impact on satisfaction toward WeChat.

H21: The level of SNS addiction has a positive impact on loyalty toward WeChat.

H22: The level of SNS addiction has a positive impact on the habit toward WeChat.

Fig. 1 presents the research model.

\section{METHODOLOGY}

\subsection{Data Collection and Sample}

Data from this study were collected from a Web-based survey of WeChat users. WeChat is a free application aiming at providing social networking services for intelligent terminal users created by Tencent in 2011. It mainly supports the addition of friends, and can send texts, pictures, videos and voice messages between friends through the mobile Internet. Meanwhile, mobile users also can use some location-based social plugins such as "shake it off", "current bottle", "circle of friends", "public platform", etc. As of the end of 2018, WeChat has more than 1 billion active users per month, with 45 billion messages sent every day and 410 million audio and video calls.

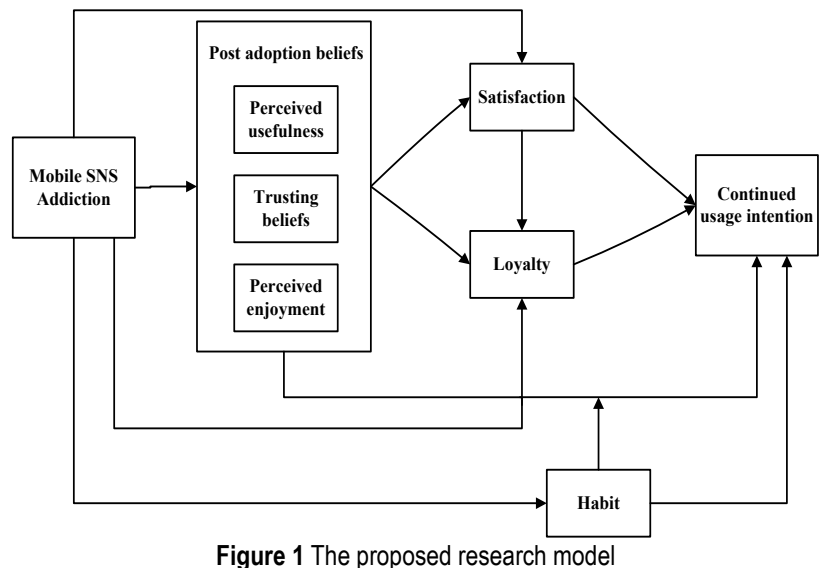

To facilitate reference to the questionnaire used in previous studies, this study used English to design the questionnaire. Later, the questionnaire was translated into Chinese to facilitate the Chinese respondents to fill out. In order to ensure the correctness and reliability of the Chinese translation results, the Chinese translation of all the items in the questionnaire was independently completed by the two authors of this study. Next, we invite a Chinese-speaking information system researcher to summarize and optimize the two results. For disputed places, the above three people will form a consensus through discussion. Before forming a formal questionnaire, we invited 50 college students with experience in WeChat from Jiangxi University of Finance and Economics to do a pre-test, which was used to improve ambiguous or poorly worded items. According to the results of the pre-test, some unclear or puzzling descriptions were modified. The official questionnaire was published through a professional survey service website called Sojump.com, which lasted four months from December 2016 to March 2017. The questionnaire was spread through e-mail, QQ, Wechat and other communication tools to allow more users to participate in our survey. In total, 579 responses were received. We scrutinized and eliminated those questionnaires, which either had too many missing values or the same answers to all questions. Finally, 495 valid responses were obtained.

As shown in Tab. 1, 44.4\% respondents were male and $55.6 \%$ were female, with $83.2 \%$ respondents between 17 and 28 years old. The majority of respondents were under 35 years old (95.6\%). 88.7\% respondents held a bachelor's degree. $97.4 \%$ respondents use WeChat for not less than half year. The results of this survey were nearly consistent with the reported by Tencent (2015). According to Tencent (2015), WeChat user sex ratio was 1.8:1, that is, male users accounted for more than $60 \%$. This group is young, with nearly half of users under 28 years old and about $90 \%$ under 35 years old. Above-mentioned descriptions provided supports for the point that our sample was not influenced by a non-response bias. 
Table 1 Descriptive statistics of respondents' characteristics

\begin{tabular}{|c|c|c|c|}
\hline Measure & Category & Frequency & $\begin{array}{c}\text { Percentage } \\
(\%)\end{array}$ \\
\hline \multirow{2}{*}{ Gender } & Male & 220 & 44.4 \\
\hline & Female & 275 & 55.6 \\
\hline \multirow{6}{*}{ Age } & 16 and under & 2 & 0.4 \\
\hline & $17-28$ & 412 & 83.2 \\
\hline & $29-35$ & 59 & 11.9 \\
\hline & $36-44$ & 15 & 3.0 \\
\hline & $45-60$ & 7 & 1.4 \\
\hline & Over 60 & 0 & 0 \\
\hline \multirow{4}{*}{$\begin{array}{l}\text { Education } \\
\text { level }\end{array}$} & Doctorate & 9 & 1.8 \\
\hline & Master's degree & 77 & 15.6 \\
\hline & Bachelor's degree & 353 & 71.3 \\
\hline & Others & 56 & 11.3 \\
\hline \multirow{5}{*}{ Time of use } & Half year & 13 & 2.6 \\
\hline & Half year-one year & 67 & 13.5 \\
\hline & One year-two years & 160 & 32.3 \\
\hline & $\begin{array}{c}\text { Two years-three } \\
\text { years }\end{array}$ & 131 & 26.5 \\
\hline & Over three years & 124 & 25.1 \\
\hline \multirow{7}{*}{$\begin{array}{c}\text { Frequency of } \\
\text { use }\end{array}$} & $\begin{array}{l}\text { Frequent use ever } \\
\text { day }\end{array}$ & 293 & 59.2 \\
\hline & $\begin{array}{c}\text { Several times ever } \\
\text { day }\end{array}$ & 114 & 23.0 \\
\hline & Once a day & 29 & 5.9 \\
\hline & $\begin{array}{c}\text { Several times a } \\
\text { week }\end{array}$ & 41 & 8.3 \\
\hline & Once a week & 2 & 0.4 \\
\hline & $\begin{array}{l}\text { Not more than one } \\
\text { time a week }\end{array}$ & 10 & 2.0 \\
\hline & $\begin{array}{l}\text { Not more than one } \\
\text { time a month }\end{array}$ & 6 & 1.2 \\
\hline
\end{tabular}

\subsection{Measurement Development}

Our questionnaire was composed of three parts. Five questions concerning demographic information shown in preceding Table 1 composed the first part. 29 items about the mobile SNS continuance usage behaviors made up the second part. They were designed to measure the constructs of perceived usefulness (5 items), trusting beliefs ( 5 items), perceived enjoyment (3 items), satisfaction (4 items), loyalty (3 items), habit (5 items) and continuance intention (4 items). Each construct items in part two and part three were measured on the 5-point Likert scales ranging from "strongly disagree" to "strongly agree".

The questionnaire exploited three different approaches to operationalize the mobile SNS addiction. Byun et al. (2009) pointed out that existing technology addiction and obsessive-compulsive disorder scales varied in the sets of addiction symptoms they captured, and consequently the space of potential measures of technology addiction was convoluted [29]. So, three different scales were selected based on their fit to the WeChat context. The first, second, and third approaches, in which addiction was operationalized by means of the Faber and O'Guinn scale (FOGS), the Charlton scale (CTAS), and the obsessivecompulsive usage scale (CUW), respectively. This treatment was similar to the study of Turel et al. (2011) [16]. Of course, we also assessed the interchangeability of measures of addiction. The correlations between addiction constructs were $r_{\text {FOGS-CTAS }}=0.78, r_{\text {FOGS-CUW }}=0.75$, and $r_{\text {CTAS-CUW }}=0.97$, all significant at $p<0.001$. These results evinced that the scales were somewhat interchangeable but not fully exchangeable, because ranges of symptoms of technology addiction they taped into were separate from each other. Therefore, three different scales for measuring mobile SNS addiction were used in this paper. The third part of the questionnaire consisted of 27 items. Among them, FOGS had 8 items; CTAS had 9 items; and CUW had 10 items.

All the construct items used in our study were selected from previously validated measurements and had been slightly modified to fit the specific context under mobile SNS. Adapted from Turel et al. (2011) [16], we used three different constructs to measure the mobile SNS addiction such as the compulsive usage scale [30], the behavioral technology addiction scale [31] and the obsessivecompulsive usage scale [32]. The scales for perceived usefulness were derived from Lin and Lu (2011) [33] while questions for perceived enjoyment came from work of Lin et al. (2014) [13]. The questions used in the trusting beliefs were derived from Gwebu et al. (2014) [16]. The measure for loyalty and satisfaction was developed from Kim (2009) [10] and Lin et al. (2014) [13] respectively. The questions used in the habit came from Chiu et al. (2012) [34]. The questions for continuance intention were derived from Mouakket (2015) [11].

\section{RESULTS}

\subsection{Testing the Validity and Reliability of Constructs}

We used the Amos 22.0 and SPSS 19.0 to test reliability and validity of the measurement model. As shown in Tab. 2, the Cronbach's alpha $(\alpha)$ values of all constructs were over the 0.70 level. Therefore, the reliability of the measurement model is acceptable.

\begin{tabular}{|c|c|c|c|}
\hline Construct & Number of items & $\begin{array}{c}\text { Cronbach's alpha } \\
(\alpha)\end{array}$ & $\begin{array}{l}\text { Reference } \\
\text { value }\end{array}$ \\
\hline $\mathrm{PE}$ & 3 & 0.926 & \multirow{10}{*}{$\begin{array}{c}\text { Cronbach } \\
\alpha \geq 0.70\end{array}$} \\
\hline $\mathrm{PU}$ & 5 & 0.890 & \\
\hline TB & 5 & 0.911 & \\
\hline SA & 4 & 0.922 & \\
\hline LO & 3 & 0.855 & \\
\hline HA & 5 & 0.956 & \\
\hline FOGS & 8 & 0.915 & \\
\hline CTAS & 9 & 0.953 & \\
\hline CUW & 10 & 0.948 & \\
\hline $\mathrm{CI}$ & 3 & 0.774 & \\
\hline
\end{tabular}

This paper used the method of confirmatory factor analysis to evaluate the convergent validity. The results show that the factor loadings of all remaining items in the three models were greater than 0.60 . The average variance extracted (AVE) values of all items except continuance intention exceed the 0.50 threshold. Moreover, since the AVE values of continuance intention in the second and third model (0.464 and 0.46 ) were close enough to 0.50 , we perceived that there was an acceptable convergence among the items of continuance intention. Besides, the square root of the average variance extracted was greater than that of other constructs. The internal consistency of the measurement model was measured by Composite reliability, and all the composite reliabilities in the three models meet the minimum required level of 0.70 (Fornell \& Larcker, 1981). Thus, all the measures were reliable and valid. 


\subsection{Testing the Hypotheses}

We exploited Structural Equation Modelling (SEM) to examine the research model and explore the relationships between the hypotheses in this study. The fit of the model was satisfactory. All the fit indices (X2/df, GFI, AGFI, RMSEA, CFI, TLI and IFI) were within the recommended values. The standardized path coefficients and path significances were displayed in Tab. 3.

Our research used the integrated model of Gwebu et al. (2014) to examine users' continuance intention toward mobile SNS. So, we compared our results with those of Gwebu et al. (2014) [14], shown in Tab. 3. Overall, except $\mathrm{H} 16$, other results (from $\mathrm{H} 1$ to $\mathrm{H} 15$ ) were similar to the study of Gwebu et al. (2014).

The results in Tab. 3 evince that except H2, H11, H15, $\mathrm{H} 20$, and $\mathrm{H} 21$, the other hypotheses are supported. Overall, the three models suggest that consistent with the proposed theory, addiction inflates one's perceptions of usefulness, enjoyment, trusting beliefs and habit. But, mobile SNS addiction is found to have no effect on satisfaction and loyalty, refuting $\mathrm{H} 20$ and $\mathrm{H} 21$.

\section{DISCUSSIONS, CONCLUSION AND LIMITATIONS}

Mobile SNS is becoming increasingly popular among individual especially younger generations. However, that excessive and uncontrolled SNS use may have negative consequences is supported by several studies. Peculiarly, engagement in mobile SNS stands a chance of turning into addictive use. This research incorporates technology addiction into continued, post-adoption technology usage decisions in the context of Mobile SNS. Our purpose is to investigate whether users' levels of addiction impacts their continuance intention to use WeChat, as one of the most popular mobile SNS in China.

Table 3 The structural model: path coefficients and their levels of significance

\begin{tabular}{|c|c|c|c|c|c|c|c|c|}
\hline \multirow{2}{*}{\multicolumn{2}{|c|}{ Hypothesis/Addiction Scale }} & \multicolumn{3}{|c|}{ Path Coefficient and Their Levels of Significance } & \multicolumn{3}{|c|}{ Hypothesis confirmed? } & \multirow{3}{*}{$\begin{array}{c}\text { Gwebu et al. } \\
(2014) \\
0178 * * *\end{array}$} \\
\hline & & FOGS & CTAS & CUW & FOGS & CTAS & CUW & \\
\hline $\mathrm{H} 1$ & $\mathrm{PU} \rightarrow \mathrm{CI}$ & $0.222 * * *$ & $0.218^{* * *}$ & $0.220 * * *$ & $\mathrm{Y}(\mathrm{Yes})$ & $\mathrm{Y}$ & $\mathrm{Y}$ & \\
\hline $\mathrm{H} 2$ & $\mathrm{~TB} \rightarrow \mathrm{CI}$ & 0.001 & 0.006 & 0.008 & $\mathrm{~N}(\mathrm{No})$ & $\mathrm{N}$ & $\mathrm{N}$ & 0.003 \\
\hline $\mathrm{H} 3$ & $\mathrm{PE} \rightarrow \mathrm{CI}$ & $0.093 * *$ & $0.096^{* *}$ & $0.097 * *$ & $\mathrm{Y}$ & $\mathrm{Y}$ & $\mathrm{Y}$ & $0.271^{* * * *}$ \\
\hline $\mathrm{H} 4$ & $\mathrm{SA} \rightarrow \mathrm{CI}$ & $0.139 *$ & $0.136^{*}$ & $0.139 *$ & $\mathrm{Y}$ & $\mathrm{Y}$ & $\mathrm{Y}$ & $0.145^{*}$ \\
\hline $\mathrm{H} 5$ & $\mathrm{LO} \rightarrow \mathrm{CI}$ & $0.145^{* *}$ & $0.149 * *$ & $0.145 * *$ & $\mathrm{Y}$ & $\bar{Y}$ & $\mathrm{Y}$ & $0.147 *$ \\
\hline $\mathrm{H} 6$ & $\mathrm{SA} \rightarrow \mathrm{LO}$ & $0.408 * * *$ & $0.398 * * *$ & $0.399 * * *$ & $\bar{Y}$ & $\mathrm{Y}$ & $\mathrm{Y}$ & $0.223 * * *$ \\
\hline $\mathrm{H} 7$ & $\mathrm{PU} \rightarrow \mathrm{SA}$ & $0.354 * * *$ & $0.374 * * *$ & $0.378 * * *$ & $\mathrm{Y}$ & $\mathrm{Y}$ & Y & $0.186^{* * * *}$ \\
\hline $\mathrm{H} 8$ & $\mathrm{~TB} \rightarrow \mathrm{SA}$ & $0.356^{* * *}$ & $0.365^{* * *}$ & $0.366^{* * *}$ & $\mathrm{Y}$ & $\mathrm{Y}$ & $\mathrm{Y}$ & $0.386^{* * *}$ \\
\hline H9 & $\mathrm{PE} \rightarrow \mathrm{SA}$ & $0.230^{* * *}$ & $0.243^{* * *}$ & $0.244 * * *$ & $\mathrm{Y}$ & $\mathrm{Y}$ & $\mathrm{Y}$ & $0.389^{* * * *}$ \\
\hline H10 & $\mathrm{PU} \rightarrow \mathrm{LO}$ & $0.410 * * *$ & $0.445 * * *$ & $0.437 * * *$ & $\mathrm{Y}$ & $\mathrm{Y}$ & $\mathrm{Y}$ & $0.153^{* *}$ \\
\hline H11 & $\mathrm{TB} \rightarrow \mathrm{LO}$ & -0.082 & -0.055 & -0.060 & $\mathrm{~N}$ & $\mathrm{~N}$ & $\mathrm{~N}$ & 0.083 \\
\hline $\mathrm{H} 12$ & $\mathrm{PE} \rightarrow \mathrm{LO}$ & $0.148 * * *$ & $0.169^{* * *}$ & $0.168^{* * *}$ & $\bar{Y}$ & $\overline{\mathrm{Y}}$ & $\mathrm{Y}$ & $0.455^{* * *}$ \\
\hline H13 & $\mathrm{HA} \rightarrow \mathrm{CI}$ & $0.083 * *$ & $0.085^{* *}$ & $0.086^{* *}$ & $\mathrm{Y}$ & $\mathrm{Y}$ & $\mathrm{Y}$ & 0.054 \\
\hline \multirow[b]{2}{*}{ H14 } & $\mathrm{PU} \rightarrow \mathrm{CI}$ & $0.237 * * *$ & $0.228 * * *$ & $0.229 * * *$ & \multirow[b]{2}{*}{$\mathrm{Y}$} & \multirow[b]{2}{*}{$\mathrm{Y}$} & \multirow[b]{2}{*}{$\mathrm{Y}$} & \multirow{2}{*}{$-0.146^{*}$} \\
\hline & $\mathrm{HA} \rightarrow \mathrm{CI}$ & $0.094 * * *$ & $0.100^{* * *}$ & $0.101 * * *$ & & & & \\
\hline \multirow{2}{*}{ H15 } & $\mathrm{TB} \rightarrow \mathrm{CI}$ & -0.003 & 0.000 & 0.001 & \multirow{2}{*}{$\mathrm{N}$} & \multirow{2}{*}{$\mathrm{N}$} & \multirow[b]{2}{*}{$\mathrm{N}$} & \multirow{2}{*}{-0.059} \\
\hline & $\mathrm{HA} \rightarrow \mathrm{CI}$ & $0.083 * *$ & $0.085^{* *}$ & $0.086^{* *}$ & & & & \\
\hline \multirow{2}{*}{ H16 } & $\mathrm{PE} \rightarrow \mathrm{CI}$ & $0.092^{* *}$ & $0.093 * * *$ & $0.094 * * *$ & \multirow[b]{2}{*}{ Y } & \multirow[b]{2}{*}{ Y } & \multirow[b]{2}{*}{ Y } & \multirow[b]{2}{*}{-0.014} \\
\hline & $\mathrm{HA} \rightarrow \mathrm{CI}$ & $0.082^{* *}$ & $0.093 * *$ & $0.084^{* *}$ & & & & \\
\hline H17 & $\mathrm{MSAD} \rightarrow \mathrm{PU}$ & $0.459 * * *$ & $0.180 * * *$ & $0.150 * * *$ & $\mathrm{Y}$ & $\mathrm{Y}$ & $\mathrm{Y}$ & \\
\hline H18 & $\mathrm{MSAD} \rightarrow \mathrm{PE}$ & $0.495 * * *$ & $0.176^{* * *}$ & $0.154 * * *$ & $\mathrm{Y}$ & $\mathrm{Y}$ & $\mathrm{Y}$ & \\
\hline H19 & $\mathrm{MSAD} \rightarrow \mathrm{TB}$ & $0.357^{* * *}$ & $0.165^{* * *}$ & $0.108^{* *}$ & $\mathrm{Y}$ & $\bar{Y}$ & $\bar{Y}$ & \\
\hline $\mathrm{H} 20$ & $\mathrm{MSAD} \rightarrow \mathrm{SA}$ & 0.021 & -0.014 & -0.034 & $\mathrm{~N}$ & $\mathrm{~N}$ & $\mathrm{~N}$ & \\
\hline $\mathrm{H} 21$ & $\mathrm{MSAD} \rightarrow \mathrm{LO}$ & 0.054 & -0.047 & -0.015 & $\mathrm{~N}$ & $\mathrm{~N}$ & $\mathrm{~N}$ & \\
\hline $\mathrm{H} 22$ & $\mathrm{MSAD} \rightarrow \mathrm{HA}$ & $0.362 * * *$ & $0.099 * *$ & $0.146^{* * *}$ & $\mathrm{Y}$ & $\mathrm{Y}$ & $\mathrm{Y}$ & \\
\hline \multirow{7}{*}{$\mathrm{R}^{2}$} & PU & 0.351 & 0.068 & 0.035 & & & & \\
\hline & TB & 0.210 & 0.057 & 0.018 & & & & \\
\hline & $\mathrm{PE}$ & 0.289 & 0.046 & 0.026 & & & & \\
\hline & SA & 0.627 & 0.548 & 0.536 & & & & \\
\hline & LO & 0.636 & 0.575 & 0.570 & & & & \\
\hline & HA & 0.581 & 0.469 & 0.469 & & & & \\
\hline & $\mathrm{CI}$ & 0.684 & 0.630 & 0.624 & & & & \\
\hline
\end{tabular}

Notes: $* * *=p<0.001 ; * *=p<0.01 ; *=p<0.05$

\subsection{Discussion of Findings}

The findings suggested that the level of SNS addiction had a positive impact on perceived enjoyment and perceived usefulness of mobile SNS. Our results were in accordance with the prior IS researchers. Huh and Bowman (2008) suggested that addicted users perceived computer games more positively than non-addicted individuals [28]. Turel et al. (2011) also pointed out that individuals with high addiction levels might actually use the system dissimilarly, in a way that was more useful and more enjoyable to them [16].

The results also showed that the level of SNS addiction had positive impacts on users' trusting beliefs toward mobile SNS. As a result, users may unreasonably minimize negatives and maximize the positive aspects of mobile SNS. His or her perceptions would be driven by emotions, such as thrill, rather than by a logical assessment. The results were consistent with the study of Turel et al. (2011), which pointed out that a successful online gambler might pay close attention to the significance of a winning episode, 
regardless of the amount of time spent online and past losses [16].

Our findings also suggested that the level of SNS addiction had a positive impact on the habit toward mobile SNS. Kim (2009) [10] and Turel et al. (2011) [16] indicated that user addiction had potential for more frequent system use. So, our results were in accordance with the technology addiction literature.

The results found that the level of SNS addiction had no impact on users' perceptions of satisfaction. The results were different from the study of Huh and Bowman (2008) [28]. Huh and Bowman (2008) pointed out that individuals who were addicted more heavily, would possess higher prior evaluations of the system [28]. These augmented evaluations served as an input to current system evaluations and would impose a higher starting point for satisfaction. However, if a user had developed dependence (i.e. an addiction) on mobile SNS, he/she became more compulsive than volitional when using the SNS [35]. Thus, addictive users will be less discerning when assessing the information quality, technical quality, social support, entertainment value, and membership policies of mobile SNS. This finding can partly explain why some users continue to use mobile SNS if they are not satisfied.

The results also found that the level of SNS addiction had no impact on users' perceptions of loyalty. Different from our results, however, Lu and Wang (2008) suggested that online game addiction and loyalty show a positive correlation [36]. They pointed out that once an addiction is formed, online gamers are more likely to stick to a particular game for a long time. That is, the loyalty was more likely to have formed [35]. However, information technology is constantly innovating, and the incidence of users switching from an information technology to its competitors is rapidly increasing [37-39]. Users will be able to switch between different IT products freely, e.g., operating systems, web browsers, office productivity software, and social networking services software. As an example, since the emergence of Sina Microblog in China in 2009, it had experienced a significant increase in the number of users and use frequency in a very short period, some of whom even became addicted [40]. However, after the emergence of WeChat, the number of Sina Microblog users began to decline in 2013 [41]. Many users had migrated from Sina Microblog to WeChat. Until 2015, Sina Microblog began to recover gradually [42]. So, frequent use or even addicted use did not necessarily enhance user loyalty to the mobile SNS.

\subsection{Theoretical Implications}

This research offers the following significant theoretical contributions. First, this research enriches existing IS literature by addressing a previously underexplored issue. On one side, most of IS literature which has focused on the positive and desirable use and interaction with SNS, however, research on the SNS addiction is far from enough. There have existed only a limited number of empirical studies concerning SNS addiction. But, these studies have focused on the formation of SNS addiction, ignoring its impacts on user behaviours. In fact, Turel et al. (2011) has posited that users' levels of technology addiction impact their reasoned IT usage decisions by changing users' belief systems [16]. On the other side, previous IS studies on technology addiction have focused on technology adoption; to date, the impact of technology addiction on users' continued use has received little attention. In fact, the use of mobile SNS has become ubiquitous. In addition, some researchers have warned of the possible harm caused by excessive use of mobile SNS. This fact leads to a lack of understanding of the impact of mobile SNS addiction on user beliefs and behaviours after adoption of mobile SNS, which is essential for understanding the continued use of mobile SNS.

Second, this research also lends support to several existing MIS and psychology theories and informs further research in these fields. Our results show that perceived usefulness, perceived enjoyment, satisfaction, loyalty and habit have important impacts on mobile users' SNS continuance intention. The integrated model of Gwebu et al. (2014) [14] is supported. Besides, a higher level of SNS addiction results in inflated positive perceptions of the system. The technology addiction constructs of Turel et al. (2011) is also supported. In fact, the existence of biases that modify an addict's perception of reality is potentially supported. It extends the logic developed in substance abuse research to behavioural addiction research, and especially to the case of technology addiction. The similarities between these different types of addiction have been noted, which provide warranties for further integration of MIS theory with addiction research.

Finally, this research can serve as a platform for future research on technology addiction, and for better understanding of addiction-driven system overuse behaviours and their effects on users and their environments.

\subsection{Implications for Practice}

For mobile SNS practitioners, this paper shows that certain technology services can be addictive, in that service suppliers may burden responsibility to folks. This study also raises the issue of potential legal liability of mobile SNS providers. Anecdotal evidence suggests that lawsuits are a possible line of action for addicted SNS users. Consequently, even though this study does not certify the viability of this issue, providers of addiction-prone technologies may consider how to minimize or prevent harm.

Providers and managers of mobile SNS services often face tremendous pressure to retain current users. For example, Tencent is faced with the problem of how to allow WeChat to maintain lasting dominance. The monthly active users and daily active users of Sina Microblog, competitor of WeChat, have been increasing drastically in the first quarter in 2016 [42]. The findings underscore that mobile SNS users are easy to become addicted, and then perceive more usefulness and enjoyment of systems. In particular, according to our results addicted users would be more accustomed to mobile SNS. But, this research also shows that frequent use or even addicted use does not enhance user satisfaction and loyalty to the system. This implies that use time and use frequency increased do not necessarily mean higher satisfaction and loyalty to a mobile SNS, perhaps certain addictive symptoms 
occurring. Once a better competitive product existed, behavior migration may happen to even addicts. So, providers of mobile SNS products need to remain ever vigilant and keep their focuses on the qualities of product and service, technology trends, and customer satisfaction, and should not pay all attention to these indexes, such as the number of users, use frequency, use time and so on.

The results manifested that because SNS addiction could affect the way users interact with SNS, it should not be disregarded. If mobile SNS users spent a lot of time on mobile SNS every day, which had affected their work, study or life, they had to judge whether addicted to SNS, even if they felt the mobile SNS very good, interesting and even developed a habit of using it. The key implications of this study stemmed from the finding that mobile SNS addiction augments system-referenced perceptions. Regulating this perception of maladaptation can be accomplished through a number of belief modification techniques suggested in the psychological literature. These methods may require tampering with IT processes to modify one's perception and reduce injury.

\subsection{Limitations and Future Research}

Of course, this study also has many limitations. First, although this study investigates the impact of mobile SNS addiction on users' continuance intention, it does not analyze the reasons for mobile SNS addiction. Furthermore, some mobile SNS such as Facebook and WeChat are multifunctional friend networking (MFN) sites. Future research should explore which functions tend to trigger user becoming addicted and disclose which impacts would lead to addiction. Second, our research focuses on the user's continued use intention, but the user's psychological perception does not necessarily have an inevitable relationship with the actual use behaviour. Third, this study is conducted in one country. Moreover, our respondents are WeChat users, and findings related to one specific site may limit generalizability to other SNS. Future research should replicate our study for other SNS, such as Facebook, and in other countries, to validate our results. Finally, future research can investigate the impacts of demographic or individual differences on mobile SNS addiction, such as age, gender, and personality traits.

\section{Acknowledgements}

This study is supported by the National Natural Science Foundation of China (grant numbers 71764006, 71363022, 71373192, 71361012), and Foundation of Jiangxi Educational Committee (grant number GJJ170335).

\section{REFERENCES}

[1] Nikou, S. \& Bouwman, H. (2014).Ubiquitous use of mobile social network services. Telematics and Informatics, 31(3), 422-433. https://doi.org/10.1016/j.tele.2013.11.002

[2] Reychav, I., Ndicu, M., \& Wu, D. (2016). Leveraging social networks in the adoption of mobile technologies for collaboration. Computers in Human Behavior, 58(5), 443453. https://doi.org/10.1016/j.chb.2016.01.011

[3] Usluel, Y. K., Kokoç, M., Sarıca, H. C., \& Akar, S. G. M. (2016). English version of Social Networks Adoption Scale:
A validation study. Telematics and Informatics, 33(2), 484492. https://doi.org/10.1016/j.tele.2015.10.007

[4] Davis, F. D. (1989). Perceived usefulness, perceived ease of use, and user acceptance of information technologies. MIS Quarterly, 13(2), 319-340. https://doi.org/10.2307/249008

[5] Pinho, J. C. M. R. \& Soares, A. M. (2011). Examining the technology acceptance model in the adoption of social networks. Journal of Research in Interactive Marketing, 5(2), 116-129. https://doi.org/10.1108/17505931111187767

[6] Zhang, L., Zhu, J., \& Liu, Q. (2012). A meta-analysis of mobile commerce adoption and the moderating effect of culture. Computers in Human Behavior, 28(5), 1902-1911. https://doi.org/10.1016/j.chb.2012.05.008

[7] Chang, Y. P. \& Zhu, D. H. (2011). Understanding social networking sites adoption in China: A comparison of preadoption and post-adoption. Computers in Human Behavior, 27(5), 1840-1848. https://doi.org/10.1016/j.chb.2011.04.006

[8] Pai, P. \& Arnott, D. C. (2013). User adoption of social networking sites: Eliciting uses and gratifications through a means-end approach. Computers in Human Behavior, 29(3), 1039-1053. https://doi.org/10.1016/j.chb.2012.06.025

[9] Ifinedo, P. (2016). Applying uses and gratifications theory and social influence processes to understand students' pervasive adoption of social networking sites: Perspectives from the Americas'. International Journal of Information Management, 36(2), 192-206. https://doi.org/10.1016/j.ijinfomgt.2015.11.007

[10] Kim, S. S. (2009). The Integrative Framework of Technology Use: An Extension and Test. MIS Quarterly, 33(3), 513-537. https://doi.org/10.2307/20650307

[11] Mouakket, S. (2015). Factors influencing continuance intention to use social network sites: The Facebook case. Computers in Human Behavior, 53(12), 102-110. https://doi.org/10.1016/j.chb.2015.06.045

[12] Zhang, Z. (2010). Feeling the sense of community in social networking usage. IEEE Transactions on Engineering Management, 57(2), 225-239. https://doi.org/10.1109/TEM.2009.2023455

[13] Lin, H., Fan, W., \& Chau, P. Y. K. (2014). Determinants of users' continuance of social networking sites: A selfregulation perspective. Information \& Management, 51(5), 595-603. https://doi.org/10.1016/j.im.2014.03.010

[14] Gwebu, K., Wang, J., \& Guo, L. (2014). Continued usage intention of multifunctional friend networking services: A test of a dual-process model using Facebook. Decision Support Systems, 67(12), 66-77. https://doi.org/10.1016/j.dss.2014.08.004

[15] Liu, Q., Zhang, F., Mao, M., Xue, B., \& Lin, Z. (2018). An empirical study on factors affecting continuance intention of using Yu'eBao. Tehnicki vjesnik, 25(5), 1414-1420. https://doi.org/10.17559/TV-20180413122553

[16] Turel, O., Serenko, A., \& Giles, P. (2011). Integrating Technology Addiction and Use: An Empirical Investigation of Online Auction Users. MIS Quarterly, 35(4), 1043-1061. https://doi.org/10.2307/41409972

[17] Maier, C., Laumer, S., Eckhardt, A., \& Weitzel, T. (2014). Giving too much social support: social overload on social networking sites. European Journal of Information Systems, 24(5), 1-18. https://doi.org/10.1057/ejis.2014.3

[18] Jeong S., Kim, H., Yum, J., \& Hwang, Y. (2016). What type of content are smartphone users addicted to?: SNS vs. games. Computers in Human Behavior, 54(1), 10-17. https://doi.org/10.1016/j.chb.2015.07.035

[19] Rosen, L. D., Whaling, K., Rab, S., Camer, L. M., \& Cheever, N. A. (2013). Is Facebook creating "iDisorders"? The link between clinical symptoms of psychiatric disorders and technology use, attitudes and anxiety. Computers in Human Behavior, 29(3), 1243-1254. https://doi.org/10.1016/j.chb.2012.11.012 
[20] Rauch, S. M., Strobel, C., Bella, M., Odachowski, Z., \& Bloom, C. (2014). Face to face versus Facebook: does exposure to social networking web sites augment or attenuate physiological arousal among the socially anxious? Cyberpsychology, Behavior, and Social Networking, 17(3), 187-190. https://doi.org/10.1089/cyber.2012.0498

[21] Kuss, D. J. \& Griffiths, M. D. (2011). Excessive online social networking - canadolescents become addicted to Facebook? Education and Health, 29(4), 68-71.

[22] Holden, C. (2001). Compulsive Behaviors: 'Behavioral' Addictions: Do They Exist?. Science, 294(5544), 980-982. https://doi.org/10.1126/science.294.5544.980

[23] Limayem, M., Hirt, S. G., \& Cheung, C. M. K. (2007). How Habit Limits the Predictive Power of Intention: The Case of Information Systems Continuance. MIS Quarterly, 31(4), 705-737. https://doi.org/10.2307/25148817

[24] Xu, H. \& Tan, B. C. Y. (2012). Why do I keep checking Facebook: Effects of message characteristics on the formation of social network services addiction? Proceedings of the $33^{\text {rd }}$ International Conference on Information Systems (ICIS), Orlando (FL), 1-12.

[25] Salehan, M. \& Negahban A. (2013). Social networking on smartphones: When mobile phones become addictive. Computers in Human Behavior, 29(6), 2632-2639. https://doi.org/10.1016/j.chb.2013.07.003

[26] Becker, G. S. \& Murphy, K. M. (1988). A Theory of Rational Addiction. Journal of Political Economy, 96(4), 675-700. https://doi.org/10.1086/261558

[27] Kim, S. S. (2009). The Integrative Framework of Technology Use: An Extension and Test. MIS Quarterly, 33(3), 513-537. https://doi.org/10.2307/20650307

[28] Huh, S. \& Bowman, N. D. (2008). Perception and Addiction of Online Games as a Function of Personality Traits. Journal of Media Psychology, 13(2), 1-26.

[29] Byun, S., Ruffini, C., \& Blanton, M. (2009). Internet Addiction: Metasynthesis of 1996-2006 Quantitative Research. Cyberpsychology \& Behavior, 12(2), 203-207. https://doi.org/10.1089/cpb.2008.0102

[30] Faber, R. J. \& O'Guinn, T. C. (1992). Clinical Screener for Compulsive Buying. Journal of Consumer Research, 19(3), 459-469. https://doi.org/10.1086/209315

[31] Charlton, J. P. (2002). A Factor-Analytic Investigation of Computer 'Addiction' and Engagement. British Psychological Society, 93(3), 329-344. https://doi.org/10.1348/000712602760146242

[32] Pallanti, S., DeCaria, C. M., Grant, J. E., Urpe, M., \& Hollander, E. (2005). Reliability and Validity of the Pathological Gambling Adaptation of the Yale-Brown Obsessive-Compulsive Scale (PG-YBOCS). Journal of Gambling Studies, 21(4), 431-443. https://doi.org/10.1007/s10899-005-5557-3

[33] Lin, K. Y., \& Lu, H. P. (2011). Why people use social networking sites: An empirical study integrating network externalities and motivation theory. Computers in Human Behavior, 27(3), 1152-1161. https://doi.org/10.1016/j.chb.2010.12.009

[34] Chiu, C. M., Chang, C. C., Cheng, H. L., \& Fang, Y. H. (2009). Determinants of customer repurchase intention in online shopping. Online Information Review, 33(4), 761784. https://doi.org/10.1108/14684520910985710

[35] Liu, Q., Zhang, X., Huang, S., Zhang, L., \& Zhao, Y. (2020). Exploring consumers' buying behavior in a large online promotion activity: the role of psychological distance and involvement. Journal of Theoretical and Applied Electronic Commerce Research, 15(1), 66-80. https://doi.org/10.4067/S0718-18762020000100106

[36] Lu, H. P. \& Wang, S. (2008). The role of Internet addiction in online game loyalty: an exploratory study. Internet Research, 18(5), 499-519. https://doi.org/10.1108/10662240810912756
[37] Liu, Q. \& Zhang, L. (2014). Information cascades in online reading: An empirical investigation of panel data. Library $\mathrm{Hi}$ Tech, 32(4), 687-705. https://doi.org/10.1108/LHT-06-2014-0052

[38] Liu, Q., Huang, S., \& Zhang, L. (2016). The influence of information cascades on online purchase behaviors of search and experience products. Electronic Commerce Research, 16(4), 553-580. https://doi.org/10.1007/s10660-016-9220-0

[39] Liu, Q., Zhang, X., Zhang, L., \& Zhao, Y. (2018). The interaction effects of information cascades, word of mouth and recommendation systems on online reading behavior: An empirical investigation. Electronic Commerce Research. https://doi.org/10.1007/s10660-018-9312-0

[40] Sina technology. (2011). Sina releasedearnings of each quarter and annual earnings in 2010 , evincing that there have been more than 100 million SinaMicro-blog users so far. Retrieved from http://tech.sina.com.cn/i/2011-03-02/ 06005233783.shtml.

[41] Oriental Morning Post. (2014). A 9 percent drop struck users of Sina Micro-blog in 2013. Retrieved from http://finance.ifeng.com/a/20140117/11492792_0.shtml

[42] Sina technology. (2016). Micro-blog' s net profit grew 5 times in the first quarter, with monthly active users increased to 261 million, Retrieved from http://tech.sina.com.cn/i/ 2016-05-12/doc-ifxsenvm0294013.shtml

\section{Contact information:}

\section{Li FANG, MSc}

College of Modern Economics \& Management, Jiangxi University of Finance and Economics, No. 169, East Shuanggang Road,

Changbei, Nanchang, Jiangxi, 330013, P. R. China 752354194@qq.com

\section{Qihua LIU, PhD}

(Corresponding author)

School of Management, Hainan University,

No. 58, Renmin Avenue,

Haikou, Hainan Province, 570228, P. R. China

qh_liu@163.com 